\title{
The youth-centricity of three university-associated general practices
}

\author{
Tim Staunton Smith
}

\begin{abstract}
Background and objectives Young people are poor attenders of mainstream general practice; however, university general practices may be an exception, given the age demographic of the population from which they draw patients. The objective of this article was to explore the youth-centricity of 12 months of encounter data from three university-associated general practices: Queensland University of Technology (QUT) in Brisbane, University of New South Wales (UNSW) in Sydney and the University of Melbourne (UniMelb).
\end{abstract}

\section{Method}

Encounter data from January to December 2016 were extracted from information management software and analysed using SPSS Statistics 24.

\section{Results}

The highest percentages of encounters were with patients aged $20-24$ years at QUT (39.8\%), UNSW (40.6\%) and UniMelb (40\%).

\section{Discussion}

The age encounter data from the general practices associated with QUT, UNSW and UniMelb demonstrate their youthcentricity, with almost $50 \%$ of encounters with patients aged $15-24$ years. This result is unsurprising given the age demographic from which these practices draw patients, but a proportional underrepresentation of younger students suggests possible access issues that require further research. Questions regarding the role of these and other Australian university-associated general practices in the health of young people attending university are signposted for future enquiry.
MOST YOUNG PEOPLE aged 15-24 years rate their health as excellent, very good or good. ${ }^{1}$ When health concerns do arise, however, young people are able to articulate those concerns, but a majority do not access healthcare. ${ }^{1,2}$

Various access barriers to healthcare for young people have been identified. These barriers include lack of knowledge of health services, inconvenient opening hours, location, cost, waiting times, confidentiality concerns, unfriendly environments, lack of doctor confidence in dealing with young people, and unavailability of a doctor of a specific gender. ${ }^{2-5}$ For marginalised young people, barriers are often higher. ${ }^{3}$

Facilitating healthcare access for young people is important; despite self-rating their health positively, significant health issues exist, and modifiable factors for future health are established or accelerate during this time. ${ }^{1}$ Examples include obesity, sexually transmitted infections, mental health conditions and risktaking behaviours leading to injury or death. ${ }^{1}$ Given higher barriers and more prevalent and complex health issues, access facilitation for marginalised young people is of particular importance. ${ }^{3}$

Young people's specific health problems and their difficulties accessing healthcare have informed a number of activities. Examples include development of best practice guidelines and complementary audits, ${ }^{6}$ training programs and resources, ${ }^{7-10}$ different models of care, ${ }^{11,12}$ policy frameworks, ${ }^{13}$ evolving advocacy organisations, such as the Australian Association for Adolescent Health, and the formation of the upcoming medical specialty adolescent and young adult medicine.

A gap in knowledge of young people's healthcare access in Australia relates to the large and increasing number of young people attending university and their use of university-associated general practices. There are currently more than 30 of these general practices operating across all Australian states and the ACT. Despite published research conducted within them, ${ }^{14}$ there is limited research specifically addressing their role in the health and healthcare access of young people studying at university. ${ }^{15}$ Given their location on or nearby Australian university campuses, these practices, presumably, see high numbers of young people, reflecting the age demographic from which they draw.

The work presented here explores the youth-centricity of three Australian university-associated general practices: Queensland University of Technology (QUT) in Brisbane, University of New South Wales (UNSW) in Sydney and the University of Melbourne (UniMelb) in Melbourne. This descriptive work provides an introduction to university-associated general practices in Australia and outlines potential future enquiries.

\section{Method}

Encounter data from January to December 2016 were extracted from information management software by practice managers using the PenCAT data tool. An individual patient attending a practice within the 12-month period was registered as a single encounter regardless of the number of times they attended.

Extracted data were de-identified by practice managers and imported into IBM SPSS Statistics 24. Initial analysis involved stratifying the encounters into five-year age brackets, and descriptive statistics were used to calculate percentages of total encounters for each age bracket. 
Monash University ethics approval was sought (project 8885). The proposal met the conditions for exemption from HREC review, and approval was granted in accordance with section 5.1.22 of the National Statement on Ethical Conduct in Human Research (2007).

\section{Results}

Five-year age-bracketed single encounters with calculated percentages of total encounters are presented in Table 1 , and percentages are illustrated in Figure 1. In 2016 , a total of 26,305 single encounters were recorded across the three university general practice sites: 5244 at QUT, 10,905 at UNSW and 10,156 at UniMelb. The highest percentages of encounters were with patients aged 20-24 years at QUT (39.8\%),
UNSW (40.6\%) and UniMelb (40\%). The second highest percentages of encounters at all sites were with patients aged 25-29 years at QUT (23.2\%), UNSW (18.3\%) and UniMelb (26.8\%). Patients aged 15-19 years accounted for $4.9 \%$ (QUT), $7.5 \%$ (UNSW) and $4.5 \%$ (UniMelb) of total encounters, ranking them fifth, fourth and fifth highest percentages for encounters at these general practices respectively.

\section{Discussion}

The intake policies of the general practices associated with QUT, UNSW and UniMelb are set to predominantly limit encounters to those drawn from their populations of students and staff. These policies, together with the knowledge that $39.7 \%$ of total higher education students are aged
20-24 years, ${ }^{16}$ make it unremarkable to find the largest percentage of encounters at QUT (39.8\%), UNSW (40.6\%) and UniMelb (40\%) general practices are also aged 20-24 years.

Furthermore, it is unsurprising that almost half of single encounters at the three general practices $(44.7 \%, 48.1 \%$ and $44.5 \%$ at QUT, UNSW and UniMelb respectively) were with young people aged $\leq 24$ years, considering that $63.2 \%$ of total higher education students are in the same age range. ${ }^{16}$ These figures confirm the youth-centricity of the universityassociated general practices included in this study; their difference from the wider Australian general practice environment is highlighted by comparison with $\mathrm{BEACH}$ data from $2015-16$, where a mere $7.9 \%$ of attendees were aged $15-24$ years. ${ }^{17}$

Table 1. Age-bracketed (years) single-encounter counts ( $n$ ) and calculated percentage of total (\%) for general practices associate with Queensland University of Technology, University of New South Wales and University of Melbourne

\begin{tabular}{|c|c|c|c|c|c|c|}
\hline \multirow[b]{2}{*}{$\begin{array}{l}\text { Age bracket } \\
\text { (years) }\end{array}$} & \multicolumn{2}{|c|}{$\begin{array}{l}\text { Queensland University } \\
\text { of Technology }\end{array}$} & \multicolumn{2}{|c|}{ University of New South Wales } & \multicolumn{2}{|c|}{ University of Melbourne } \\
\hline & $\mathrm{n}$ & $\%$ & $\mathbf{n}$ & $\%$ & n & $\%$ \\
\hline $0-4$ & 33 & 0.6 & 252 & 2.3 & 163 & 1.6 \\
\hline $10-14$ & 1 & 0 & 49 & 0.4 & 31 & 0.3 \\
\hline $15-19$ & 255 & 4.9 & 818 & 7.5 & 455 & 4.5 \\
\hline $20-24$ & 2,088 & 39.8 & 4,424 & 40.6 & 4,065 & 40.0 \\
\hline $25-29$ & 1,219 & 23.2 & 1,993 & 18.3 & 2,723 & 9.7 \\
\hline $40-44$ & 197 & 3.8 & 346 & 3.2 & 268 & 2.6 \\
\hline $45-49$ & 133 & 2.5 & 237 & 2.2 & 179 & 1.8 \\
\hline $50-54$ & 114 & 2.2 & 215 & 2.0 & 120 & 1.2 \\
\hline $55-59$ & 63 & 1.2 & 241 & 2.2 & 106 & 1.0 \\
\hline $60-64$ & 78 & 1.5 & 212 & 1.6 & 65 & 0.6 \\
\hline $65-69$ & 27 & 0.5 & 166 & 1.5 & 14 & 0.1 \\
\hline$\geq 70$ & 15 & 0.3 & 163 & 1.5 & 20 & 0.2 \\
\hline
\end{tabular}


In addition to drawing from a young demographic, the location and billing policies of QUT, UNSW and UniMelb general practices are likely contributors to their youth-centricity. All three practices are located on or near their university campuses, bulk bill domestic students and charge no out-of-pocket costs for the majority of international students by directly billing overseas students' medical insurers. Location and cost are known access barriers, particularly for marginalised young people. ${ }^{3}$

However, if the youth-centricity of the three general practices were simply a reflection of billing policy, location and the age demographic from which they draw, then young people aged 15-19 years appear under-represented. Although $23.5 \%$ of total higher education students are aged 19 years or younger, ${ }^{16}$ they accounted for only $4.9 \%$ (QUT), 7.5\% (UNSW) and 4.5\% (UniMelb) of encounters at the three universityassociated general practices. This suggests potential access barriers for younger students. Further investigation could involve auditing against the Youth Health Better Practice framework ${ }^{6}$ in addition to qualitative data collected from practice attenders and non-attenders.

Obtaining age enrolment data from QUT, UNSW and UniMelb would strengthen future conclusions connecting youth-centricity of their general practices to the age pool from which they draw. The author considers total higher education enrolments sufficient for initial descriptive work, given $93 \%$ of higher education enrolments are university students. ${ }^{16}$
Conclusions attributable to the data collected for this study are limited to age demographic. Collecting encounter demographics such as residency status (international versus domestic), student status (undergraduate versus postgraduate), socioeconomic status and minority status is required to identify frequency of use and potential access barriers on the basis of characteristics other than age. Although components of the Youth Health Better Practice framework and related audit tools consider known marginalised groups, additional audit tools and guidelines exist ${ }^{18,19}$ and could be used and adapted to assess access of these groups to the general practices.

A further limitation of the data collected for this study is the inability, except for age, to comment on the health and risk

\section{Age bracket (years) with percentage of total encounters}

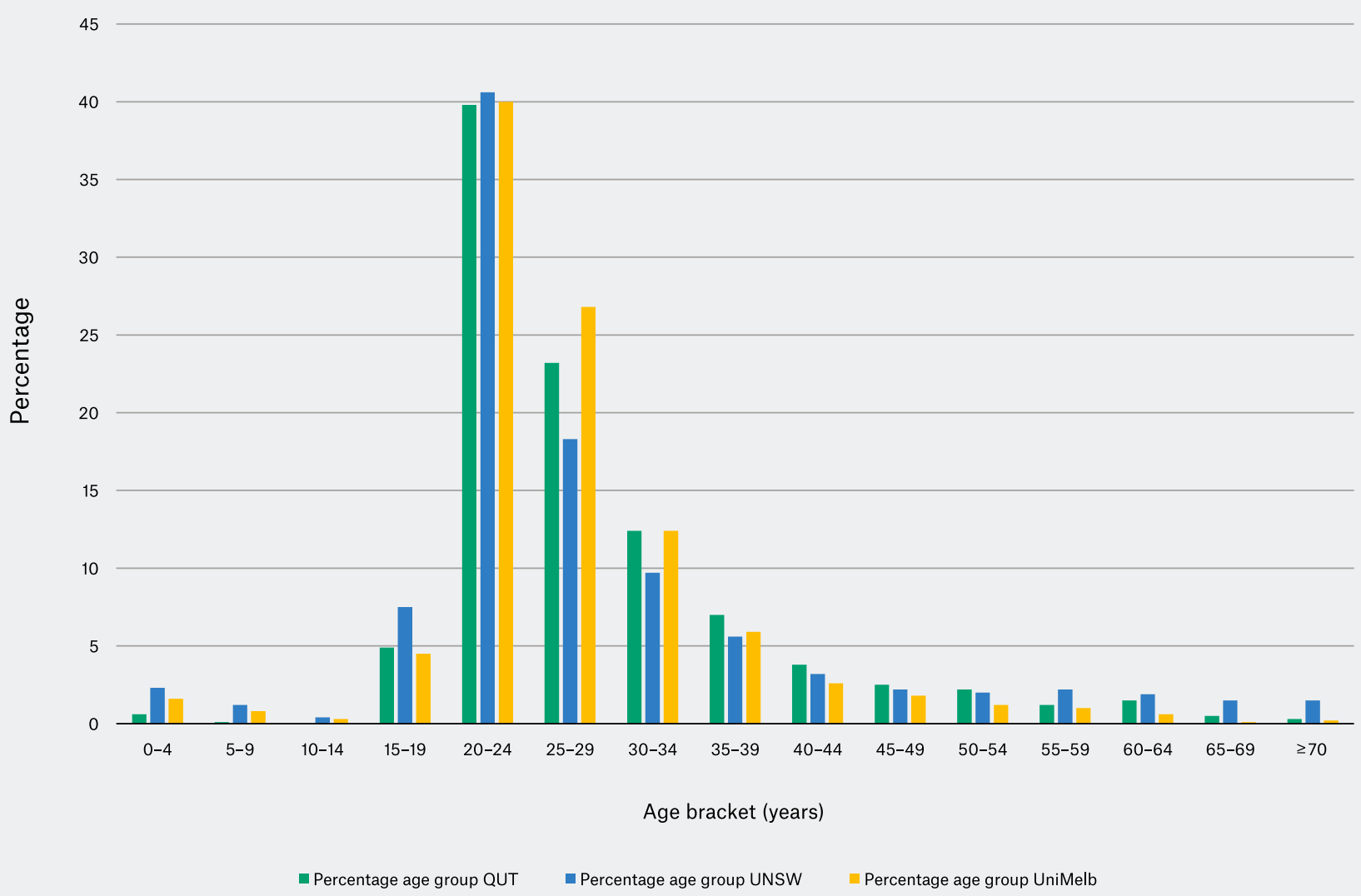

Figure 1. Age-bracketed (years) single encounters as a percentage of total counts for general practices associate with Queensland University of Technology (QUT), University of NSW (UNSW) and University of Melbourne (UniMelb) 
profiles of the attendees. It is uncertain whether known health issues and risk behaviours of young people, including marginalised young people, are mirrored by the attendees of QUT, UNSW and UniMelb general practices. Future investigation of these characteristics and healthcare access would enable comment on the part these practices may play in the health of young people attending the three universities, as well as guide local needsbased health promotions and changes within the practices.

The challenge of enabling healthcare access for young people has led to the evolution of alternative health service models, such as general practitioners in schools and youth mental health services. ${ }^{11,12}$ The youth-centricity illustrated by the age-demographic data from the urban QUT, UNSW and UniMelb general practices raises questions regarding the generalisability of youth-centricity to other universityassociated general practices, in addition to the possibility that these universityassociated general practices represent a yet undescribed youth-centric health service model.

To answer these questions, wider demographic data collection involving more Australian university-associated general practices from both urban and regional settings is required, coupled with an analysis of their structural frameworks. Similarly, wider collection of the health and risk behaviour characteristics of attendees of Australia-wide university-associated general practices would enable comment on their broader role in the health of young people attending Australian universities.

Despite limited conclusions drawn from the simple data set collected for this study, the described youth-centricity might be relevant to clinicians seeking to work in practices with a significant clinical exposure to young people. Moreover, if the youth-centricity of the three practices associated with QUT, UNSW and UniMelb is generalisable to the Australia-wide network of universityassociated general practices, there may be interest among organisations looking for opportunities for trainees to gain experience managing young people in a primary healthcare setting.

\section{Conclusion}

The demonstrated youth-centricity of the general practices associated with QUT, UNSW and UniMelb contrasts with traditional general practice and begins to fill a gap in the knowledge of Australian university-associated general practices. Possible reasons for their youth-centricity include the age demographic from which they draw, their locations and billing policies. However, the apparent underrepresentation of younger students raises the possibility of access barriers and indicates a need for further research. In addition, questions for future enquiry have been signposted to clarify the role that these and other Australian universityassociated general practices play in the health of young people attending university.

\section{Declaration: Dr Staunton Smith has worked as a general practitioner at all three of the university-associated general practices described in the paper. He also recently commenced part-time work as a GP at Swinburne University Health Service, Hawthorn, Victoria.}

\section{Author}

Tim Staunton Smith MBBS, FRACGP, MPH, Senior Lecturer, Monash Rural Health, Latrobe Valley and West Gippsland, Traralgon West, Vic. timothy. stauntonsmith@monash.edu

Competing interests: None.

Provenance and peer review: Not commissioned, externally peer reviewed.

\section{References}

1. Australian Institute of Health and Welfare. Australia's health 2014: In brief. Cat no. AUS 181. Canberra: AlHW, 2014.

2. Booth ML, Bernard D, Quine S, et al. Access to health care among Australian adolescents: Young people's perspectives and their sociodemographic distribution. J Adolesc Health 2004;34(1):97-103.

3. Cummings $M$, Kang $M$. Youth health services: Improving access to primary care. Aust Fam Physician 2012;41(5):339-41.

4. Bernard D, Quine S, Kang M, et al. Access to primary health care for Australian adolescents: How congruent are the perspective of health service providers and young people, and does it matter? Aust N Z J Public Health 2004;28:487-92.

5. Kang M, Bernard D, Booth M, et al. Access to primary health care for Australian young people: Service provider perspectives. Br J Gen Pract 2003;53(497):947-52.
6. NSW Centre for the Advancement of Adolescent Health. ACCESS study. Youth health - Better practice framework fact sheets, 2nd edn. Westmead, NSW: NSW CAAH, 2011. Available at www.health.nsw.gov.au/kidsfamilies/youth/ Pages/Better-Practice-Resources.aspx [Accessed 23 October 2017].

7. University of Melbourne. Prevention, access, and risk taking in young people. Melbourne: University of Melbourne, 2016. Available at www.party. unimelb.edu.au [Accessed 23 October 2017].

8. NSW Office of Kids and Families. Essential youth healthcare skills training manual. Sydney: NSW Health, 2016. Available at www.kidsfamilies.health. nsw.gov.au/media/336794/essential-youthhealthcare-skills-training-manual-w-tabs.pdf [Accessed 23 October 2017].

9. Chown P, Kang M, Sanci L, NewnhamV, Bennett DL. Adolescent health: Enhancing the skills of general practitioners in caring for young people from culturally diverse backgrounds, GP resource kit. 2nd edn. Sydney, NSW Centre for the Advancement of Adolescent Health and Transcultural Mental Health Centre, 2008. Available at www.schn.health.nsw.gov.au/files/ attachments/complete_gp_resource_kit_0.pdf [Accessed 23 October 2017].

10. NSW Centre for the Advancement of Adolescent Health. Youth friendly general practice training toolkit. Westmead, NSW: NSW CAAH, 2013. Available at www.kidsfamilies.health.nsw.gov.au/ media/289202/youth-friendly-general-practicetraining-toolkit.pdf [Accessed 23 October 2017].

11. Kang M, Bernard D, Usherwood T, et al. Primary health care for young people: Are there models of service delivery that improve access and quality? Youth Studies Australia 2006;25:49-59.

12. McGorry PD. The specialist youth mental health model: Strengthening the weakest link in the public mental health system. Med J Aust 2007;187(7 Suppl):S53-56.

13. NSW Department of Health. Youth health policy 2011-2016: Healthy bodies, healthy minds, vibrant futures. Sydney: Office of Kids and Families, 2010.

14. Stallman HM. Prevalence of psychological distress in university students: Implications for service delivery. Aust Fam Physician 2008;37(8):673-77.

15. Staunton Smith T, Lim D. Australian university general practices: Potential to reach out to vulnerable young people. Australas Med J 2017;10(3):247-48.

16. Department of Education and Training. Higher education all student enrolment tables for the 2016 full year. Canberra: Department of Education and Training, 2017. Available at https://docs. education.gov.au/documents/2016-all-students [Accessed 23 January 2018].

17. Britt H, Miller GC, Henderson J, et al. General practice activity in Australia 2015-16. General practice series no. 40. Sydney: Sydney University Press, 2016.

18. one21seventy and beyondblue. Youth health clinical audit tool; 2014 release. Indigenous youth audit tool. Available at www.one21seventy.org.au [Accessed 23 October 2017].

19. Gay and Lesbian Health Victoria. GLBTI-inclusive practice audit for health and human services. Melbourne: La Trobe University, 2013. Available at www.glhv.org.au/files/glhv_audit_tool_2013_1.pdf [Accessed 23 October 2017]. 